\title{
Challenges at the Time of COVID-19: Opportunities and Innovations in Antivirals from Nature
}

Authors

Andreas Hensel ${ }^{1}$, Rudolf Bauer ${ }^{2}$, Michael Heinrich ${ }^{3}$, Verena Spiegler ${ }^{1}$, Oliver Kayser ${ }^{4}$, Georg Hempel ${ }^{5}$, Karin Kraft ${ }^{6}$

Affiliations

1 Institute of Pharmaceutical Biology and Phytochemistry, University of Münster, Münster, Germany

2 Institute of Pharmaceutical Sciences, University of Graz, Graz, Austria

3 Pharmacognosy and Phytotherapy, UCL School of Pharmacy, London, UK

4 Technical Biochemistry, TU Dortmund University, Dortmund, Germany

5 Institute of Pharmaceutical and Medical Chemistry, Clinical Pharmacy, University of Münster, Münster, Germany

6 University Medicine Rostock, Chair of Complementary Medicine, Rostock, Germany

Key words

COVID, Coronaviridae, Echinacea, Asteraceae, virus, tannins, lignans, anti-adhesion, immune system, phytotherapy

$\begin{array}{ll}\text { received } & \text { April 20, } 2020 \\ \text { revised } & \text { May 5, 2020 } \\ \text { accepted } & \text { May 13, } 2020\end{array}$

Bibliography

DOI https://doi.org/10.1055/a-1177-4396

published online May 20, 2020 | Planta Med 2020; 86: 659-

664 @ Georg Thieme Verlag KG Stuttgart · New York I

ISSN 0032-0943

Correspondence

Prof. Dr. Andreas Hensel

Institute of Pharmaceutical Biology and Phytochemistry,

University of Münster

Corrensstraße 48, 48149 Münster, Germany

Phone: + 492518333381 , Fax: + 492518338341

ahensel@uni-muenster.de

\section{ABSTRACT}

As viral infections are an increasing threat to human societies, the need for new therapeutic strategies is becoming even more obvious. As no vaccine is available for COVID-19, the development of directly acting antiviral agents and preventive strategies have to be considered. Nature provides a huge reservoir of anti-infectious compounds, from which we can deduce innovative ideas, therapies, and products. Anti-adhesive natural products interact with the receptor-mediated recognition and early interaction of viruses with the host cells, leading to a reduced internalisation of the virus and reduced infections (e.g., procyanidin-B-2-di-O-gallate against influenza and herpes virus). Lignans like podophyllotoxin and bicyclol show strong antiviral activities against different viruses, and essential oils can directly interact with viral membranes and reduce the host's inflammatory responses (e.g., 1,8-cineol). Echinacea extracts stimulate the immune system, and bioavailable alkamides are key players by interacting with immunomodulating cannabinoid receptors. COVID-19 and SARS-CoV-2 infections have, in part, successfully been treated in China by preparations from traditional Chinese medicine and, while it is too early to draw conclusions, some promising data are available. There is huge potential, but intensified research is needed to develop evidence-based medicines with a clearly defined chemical profile. Intensified research and development, and therefore funding, are needed for exploiting nature's reservoir against viral infections. Combined action for basic research, chemistry, pharmacognosy, virology, and clinical studies, but also supply chain, sustainable sourcing, and economic aspects have to be considered. This review calls for intensified innovative science on natural products for the patients and for a healthier world!

\section{Results}

Since early 2020 coronaviruses, mainly severe acute respiratory syndrome (SARS)-CoV-2, have become a global concern, and also SARS-CoV-1 and MERS-CoV caused epidemic problems in former years. For many many decades, influenza viruses have been a plague, rhinoviruses and the annual cold, adenoviruses, respiratory syncytial virus (RSV) and bronchial diseases caused many problems - virus particles do indeed make our lives difficult. The use of potent antiviral drugs is possible in some cases and is also established within relevant therapies (e.g., against influenza), but - and this is the bad news - against most viral pathogens in the throat and upper airways, we do not have specific and highly effective substances. On the other hand, there could well be ways to protect oneself going beyond general public health recommendations. While currently all sorts of claims are being advocated in the popular press, here we call for a careful assessment of what 
might be meaningful adjuvant approaches, especially in milder forms of such respiratory infections.

For example, enveloped viruses (e.g., coronavirus, influenza virus, or RSV) have an envelope of a lipid bilayer derived from cellular membrane systems of the host cell [1]. These virus envelopes are relatively easily attacked by many exogenous compounds (e.g., solvents, detergents, lipophilic substances such as essential oils). The lipid layer often also contains (glyco)proteins, which can protrude in an exposed manner [1]. In many cases, these proteins are responsible for the highly specific recognition of the respective host cells, the associated physical interactions, the subsequent adhesion, and thus ultimately also for the invasion of the virus into the host cell [2]. Well-known examples are the haemagglutinin of influenza viruses [3] or the S-proteins of coronaviruses [4]. The typical point of entry for such pathogens via droplet infection is the nasopharynx. For influenza viruses, the subsequent colonisation of the epithelia is more likely to occur in the bronchial area, whereas COVID-19 infections, for example, become manifest by interaction of the viral envelope proteins with complementary binding structures in the throat area.

Why not consider protecting the mouth and throat area against the penetration of such virus particles? Enveloped virus particles can be attacked by exogenous noxae - would it be conceivable to achieve a certain degree of protection through a topical treatment of the oral mucosa? In the field of natural substances, we know some drugs that contain large amounts of tannins. This very heterogeneous group of natural substances includes the proanthocyanidins (syn. condensed tannins), hydrolysable tannins (syn. gallotannins), and the so-called Lamiaceae tannins (depsides). They all have in common that they interact with proteins and are able to considerably change or inhibit protein structure and functionality. Tannins therefore often have nonspecific antimicrobial effects but can also inhibit the functionality of viral envelope proteins. Inhibitory effects of condensed tannins or extracts containing tannins on the influenza virus or RSV are known from several publications [5,6]. Mechanistic investigations using a purified proanthocyanidin (procyanidin B2-3-O-digallate) showed that this polyphenol rather specifically inhibits the binding domain of haemagglutinin of the influenza A virus, which makes it impossible for the virus particle to adhere to the host cell [7]. Similar effects have also been reported against herpes simplex viruses (HSV-1), where the corresponding adhesion proteins in the virus envelope could as well be considered as a target [8-10]. Such proanthocyanidins are quite widespread in the medicinal plant sector (e.g., green tea, common sorrel, Cistus spp., Pelargonium spp., etc.). Of course, these plants cannot be used as a therapeutic agent for manifesting viral infections. In the authors' view, it would be quite conceivable to use dosage forms to locally apply concentrated tanning extracts for local application in the oral cavity for prophylaxis and as an adjuvant therapy (provided that there are no risks of interactions). Sorrel prepared as lozenges or chewing gums, which contain proanthocyanidins in the highest possible concentration, offer such opportunities. In addition, other pharmaceutical preparations like gargle and mouthwash solutions containing such extracts have been used locally and traditionally and may offer novel opportunities. One could argue that such prophylactic methods only offer short-term protection as long as the lozenge is sucked, or the gargle solution is kept in the mouth. However, one can expect that such preparations reduce the pathogen load in the oral cave and these measures could be used during a possible exposure or immediately thereafter. There are further possible points of attack, but this would have to be further substantiated by specific investigations, especially in human volunteer studies. Tannins also interact with protein components in the oral cavity, e.g., salivary proteins and with surface proteins of the mucous membrane epithelia [11]. Everyone is certainly aware of the change in how the mouth feels after ingestion of preparations containing tannins (e.g., long-brewed black tea). In principle, this is due to tannin interactions on and with the epithelial cells, i.e., we slightly tan the buccal and tongue surface easily. The tannins are naturally immobilized on the epithelia, so they should be present for a longer period of time and perhaps also retarded. Perhaps this could also inhibit an incoming virus from adhering? This remains to be investigated, but there is a good chance that this hypothesis could be correct.

In addition, lignans play an important role as potential drug candidates for the development of antiviral compounds. Highly active representatives of this natural product class are podophyllotoxin, a typical lignan from the group of the arylnaphatelenes, and biclycol, belonging to the uncommon subclass of dibenzocyclooctenes, which are highly active against HIV and human papillomavirus (HPV) in vitro [12]. These natural products have been clinically studied for their antiviral activity against venereal warts and hepatitis B causing chronic hepatitis B.

Podophyllotoxin was found and validated as a potential antineoplastic natural product [12]. This lignan has already been mentioned as a drug against topical venereal warts (Condyloma acuminatum) caused by DNA papillomaviruses (HPV) in 1942 [13] in regulated drugs. Podophyllotoxin is also the active ingredient in Condylox liquids and Wartec ointments, registrated for the treatment of anogenital warts and anogenital warts in immunocompetent patients.

Bicyclol was shown to have antiviral activity in vitro but also in vivo in patients with hepatitis B virus (HBV) infection. Preliminary studies in mice have started using a combination of bicyclol and heat shock proteins as a potential adjuvant and, in some reports, the wide use in China since 2004 is mentioned [14]. Bicyclol might be active against the hepatitis $\mathrm{C}$ virus (HCV) as well, but contractionary data published do not give full evidence for the safety and efficacy of the drug [15]. The mechanism is still unclear, although modulation of MHC-I-mediated cytotoxicity of T cells against virus infected cells is discussed. In the case of HIV-1, lignans have been shown to inhibit reverse transcriptase activity [16]. Schröder et al. [16] conducted structure-activity studies on various lignans and showed that the lactone pharmacophore is essential and later, Eich et al. [17] documented that the pattern and number of aromatic hydroxyl substituents are important for the antiviral activity as well. Besides these two most important lignans, others have been studied and tested as well. Some with significant antiviral activities are listed in > Table $\mathbf{1}$.

Besides tannins, certain essential oils also appear to have antiviral potential against enveloped viruses $[18,19]$. In addition, in this case, the interaction with viral envelope proteins, which reduces the docking or uptake of the viruses into the cell, is of par- 
- Table 1 Lignans tested for antiviral activity.

\begin{tabular}{|c|c|c|c|c|}
\hline Name & Source & Virus & Activity $\left(\mathrm{IC}_{50}\right)$ & Literature \\
\hline Niranthin & Phyllanthus niruri L., Euphorbiaceae & HBV & $15.6-25.1 \mu \mathrm{M}$ (in vitro) & {$[46,47]$} \\
\hline NDGA & $\begin{array}{l}\text { Larrea tridentata (DC.) Coville, } \\
\text { Zygophyllaceae }\end{array}$ & $\begin{array}{l}\text { HCV } \\
\text { WNV } \\
\text { ZIKV }\end{array}$ & $\begin{array}{l}30 \mu \mathrm{M} \\
7.9 \mu \mathrm{M} \\
9.1 \mu \mathrm{M}\end{array}$ & {$[48,49]$} \\
\hline TMP & $\begin{array}{l}\text { Larrea tridentata (DC.) Coville, } \\
\text { Zygophyllaceae }\end{array}$ & $\begin{array}{l}\text { HSV-1 } \\
\text { HIVA }\end{array}$ & $\begin{array}{l}43.5 \mu \mathrm{M} \\
25 \mu \mathrm{M}\end{array}$ & {$[49,50]$} \\
\hline Yatein & $\begin{array}{l}\text { Chamaecyparis obtusa (Siebold \& Zucc.) } \\
\text { Endl., Cupressaceae }\end{array}$ & HSV-1 & $30.6 \pm 5.5 \mu \mathrm{M}$ & {$[51]$} \\
\hline DGP & Justicia gendarussa Burm.f., Acanthaceae & $\begin{array}{l}\text { ZIKV } \\
\text { HIV-1 }\end{array}$ & $\begin{array}{l}0.01-0.07 \mu \mathrm{M} \\
15-21 \mu \mathrm{M}\end{array}$ & {$[52,53]$} \\
\hline Diphyllin & & ZIKV & $0.06 \mu \mathrm{M}$ & [52] \\
\hline Bicyclol & $\begin{array}{l}\text { Schisandra rubriflora Rehder \& E. H. } \\
\text { Wilson, Schisandraceae }\end{array}$ & $\begin{array}{l}\mathrm{HBV} \\
\mathrm{HCV}\end{array}$ & $30 \mu \mathrm{M}$ & [54] \\
\hline Rubrifloralignan A & $\begin{array}{l}\text { Schisandra rubriflora Rehder \& E. H. } \\
\text { Wilson, Schisandraceae }\end{array}$ & HIV & $40.4 \mu \mathrm{M}$ & [55] \\
\hline $\begin{array}{l}\left.7^{\prime} R, 8^{\prime} S, 7 " R, 8^{\prime \prime} S\right) \text {-Erythro- } \\
\text { strebluslignanol G }\end{array}$ & Streblus asper Lour., Moraceae & $\mathrm{HBV}$ & $3.7-14.7 \mu \mathrm{M}$ & [56] \\
\hline Hinonkin & $\begin{array}{l}\text { Chamaecyparis obtusa (Siebold \& Zucc.) } \\
\text { Endl., Cupressaceae }\end{array}$ & $\begin{array}{l}\text { HCYVIE } \\
\text { SARS-CoV }\end{array}$ & $\begin{array}{l}<28 \mu \mathrm{M} \\
>10 \mu \mathrm{M}\end{array}$ & {$[47,57]$} \\
\hline
\end{tabular}

ticular importance. Most of the investigations were performed on herpes simplex viruses (HSV-1/2), but for 1,8-cineol, the main component of eucalyptus oil, protective effects were also observed in mice infected with influenza virus C (IFV-C) [20]. These effects seem to be mainly caused by a reduction of the inflammatory reactions that affect the lungs during pneumonia rather than by a direct antiviral effect. Some high-quality preparations are available in some markets, and there is a huge potential for improved and novel products. Furthermore, of course, there are substantial differences in the phytochemical composition and thus in the biological activity of essential oils. An interesting example in the current situation is the in vitro activity of laurel oil against SARS-CoV. The essential oil from the aerial parts of the laurel tree (Laurus nobilis) inhibited the replication of the virus in vitro more strongly than other essential oils from other species investigated [18]. Laurel oil contains larger amounts of the monoterpenes 1,8cineol and $\beta$-ocimen and the sesquiterpene dehydrocostus lactone [18]. However, sage oil, rich in 1,8-cineol, showed a weaker effect [18]. Inhalative applications of laurel oil would therefore be conceivable here, but its allergenic potential should be considered. In addition to essential oil, sage leaves (Salvia officinalis L.) contain tannins (depsides), so preparations such as gargle solutions could also be applied successfully.

So why not investigate and develop novel pharmaceutical preparations at a time of a hardly controllable virus pandemic? Why not simply develop lozenge preparations containing tannins or essential oils or try appropriate gargling or rinsing solutions? Not as medicines, as in this case we would need official approvals, but simply as a food supplement, albeit with a sound scientific and specifically pharmacological and pharmaceutical basis.
In the current situation with a shortfall of surgical masks, there is an urgent need for protection strategies for populations at high risk such as the elderly, immunocompromised patients, or patients with respiratory disease as well as for personnel in nursing homes, ambulatory care, and hospitals. Placebo-controlled randomised clinical trials to assess the efficacy of shelter strategies using natural products are ethically problematic to conduct in groups at high risk for infection. This would mean to withhold a possible effective product in half of the subjects. However, the use of such preparations in high-risk groups could be accompanied by non-interventional observational studies. This could gain at least some knowledge on the feasibility of such a protection strategy using natural products.

What about activating a compromised immune system by natural products or medicinal plants? It is primarily our immune system that protects us from viral infections. As soon as the immune system notices a viral infection, it begins to fight the invaders, for example, with antibodies and proteins that prevent docking and penetration into the cells [21]. These blocked viruses are then rendered harmless by various leukocytes. Host cells that are already infected by viruses begin to produce interferon and release it to neighbouring cells, which slows down the multiplication of viruses. Interferons also attract natural killer (NK) cells that detect and eliminate virus-infected cells [22,23]. Anything that weakens the immune system, therefore, makes us more susceptible to colds and viral infections. Also, with advancing age, starting at about 60 years, the formation of B-and T-lymphocytes is reduced, resulting in a higher susceptibility to infections. It is of special interest in the current situation that obesity also obviously impairs the functionality of NK cells [24]. 
Therefore, modulation of the immune system may be a promising approach in the prevention of viral infections [25]. However, since the pathology of late-stage SARS is associated with an overreaction of the immune system and a cytokine storm with symptoms of sepsis $[26,27]$, only stimulating the immune system may also be a risk.

There are many natural products and medicinal plants that are supposed to modulate immune functions [28,29]. Preparations from Echinacea species are probably most widely used and best investigated. They have traditionally been used against sepsis and have shown direct antiviral effects under in vitro conditions, and also modulatory effects on macrophages and NK cells [30-33]. Some of them have been clinically effective in the prevention and treatment of viral infections [34-36]. There has also been intensive research on the active principles. Alkamides seem to play a major role. They are readily bioavailable and bind to cannabinoid receptors, which are the key to stimulating the immune system $[37,38]$. Therefore, Echinacea is an excellent example of how natural product research from bench to bedside can create a lot of scientific evidence for the usefulness of herbal medicine in viral infections. There are many more such plants used in global ethnomedicine that still wait for evaluation.

Globally, local and traditional medicines remain a major source of health care [39]. In China, traditional Chinese medicine (TCM) has already played an important role treating SARS-CoV and SARSCoV2 infections. During the first SARS epidemic in Guangdong, all patients received Chinese medicine treatments over different stages of the disease in addition to biomedical treatments. The most commonly used formulations were San Ren Tang, Yin Qiao San, Ma Xing Shi Gan Tang, Gan Lu Xiao Du Dan, and Qing Ying Tang, containing mixtures of many different herbs. In Hong Kong, a combination of Sang Ju Yin and Yu Ping Feng San, plus two other botanicals, Isatidis folium (Isatis tinctoria L.) and Scutellariae radix (Scutellaria spp.), have been used with success to protect high-risk hospital workers against Sars-CoV infection [40]. According to a survey from 2007 [41], during the first SARS-CoV crisis in China, 40 to $60 \%$ of the infected patients received Chinese medicine treatment on top of standard modern medicine treatment at some stages of the disease. The results indicate positive but inconclusive indications about the efficacy of the combined treatments using Chinese medicine as an adjuvant [41]. Evaluation of the published literature within this study for the observed positive effects point to better control of fever, quicker clearance of chest infection, lesser consumption of steroids, and relief of other symptoms [41]. On the other side, many more clinical studies have to be performed with Chinese medicinal preparations as an adjuvant to provide adequate evidence-based therapeutic concepts.

During the recent SARS-CoV-2 infections, TCM has been again widely applied in China. According to a recent report, more than $85 \%$ of SARS-CoV-2 infected patients have received TCM treatment in China [42]. The used formulations and natural products have been recently reviewed [42]. In one survey, Luo et al. [43] found that Astragalus membranaceus (Astragalus mongholicus Bunge), Glycyrrhizae uralensis Fisch. ex DC., Saposhnikovia divaricata (Turcz. ex Ledeb.) Schischk., Atractylodis macrocephalae Koidz. (rhizome), Lonicerae japonica Thunb. (flower), Forsythia suspensa
(Thunb.) Vahl (fruit), Atractylodes lancea (Thunb.) DC. (rhizome), Platycodon grandiflorus (Jacq.) A.DC. (root), Agastache rugosa (Fisch. \& C. A.Mey.) Kuntze, and Cyrtomium fortunei J. Sm. were the ten most commonly used Chinese medicinal plants in the treatment of COVID-19. Yang et al. [42] concluded that more and better controlled clinical studies are needed to evaluate the efficacy of TCM in the treatment of SARS-CoV. In addition, standardised products should be used rather than self-prepared formulations. They also recommended that the safety of TCM treatment should be evaluated. It shows that there is huge potential, but a lot of basic and clinical research is still needed to understand the mechanisms of action in order to end up in evidence-based medicine. Importantly, the underlying philosophical concepts differ [44] and it is certainly difficult to assess many of these approaches in bioscientific terms. At the same time, it would be negligent to just ignore this large body of scholarship and, more importantly, the widespread use of preparations derived from, in this case, TCM. There is a tremendous research agenda with which we need to engage, and this will be a core task for research to develop novel therapeutic approaches.

Medicinal plants and natural products provide a huge potential to fight against pathogens! During evolution, plants and also other organisms have developed excellent and highly efficient defence mechanisms and antipathogenic defence compounds. We should strengthen activities to explore and to develop this potential. This needs more and intensified science for pinpointing the active medicinal plants, identifying active compounds, and investigating potential synergistic effects when dealing with complex mixtures. We also have to explore the chemistry behind the active ingredients. We have to develop sustainable technology for efficient production (not only milligrams are needed, but economically relevant amounts at affordable prices), and we have to initiate preclinical, toxicological, and clinical trials. There is definitely a long way to a more evidence-based phytotherapy or integration of highly active natural products into clinical practice.

Key players should not be individual scientists in their "ivory tower", but much more coordinated consortia including biologists, pharmacognosists, natural product chemists, synthetic chemists, toxicologists, clinicians, and governmental officers. Nature provides us with a huge reservoir of great antipathogenic resources, we just have to raise this treasure [45]. It is worth a try.

We also want to caution against the increasing drive for exotic medicines and supplements, often with high-level claims and a low level of evidence. Numerous products are advocated, and there can be no doubt that there is a need to develop novel products, but there can be no quick fix solution without a detailed scientific investigation of the quality, safety, pharmacological effects, and therapeutic benefits.

We also have to urgently develop research on medicinal plant production and the respective sourcing. Initial evidence points to an increase in the demand of many popular herbal substances. Medicinal plants such as Echinacea (see above) are seeing a dramatic rise in demand, but this cannot be met with the existing supply systems. This raises important questions about the integrity of the value chains relevant for the production of such health care products. The challenges are multiple, from an increased demand on the consumer side to problems related to the health of 
the workers along the value chains. We do not know yet how this is affected by the pandemic. Not only the breeding and production of the materia prima, but also the supply with authentic high-quality finished products will need much more attention as a consequence of this global challenge.

Let us start working - for an innovative science, for the patients, and for a healthier world. Clearly it is also essential that adequate funding is made available to ascertain that the potential of natural products and herbal medical products is explored in greater detail.

\section{Conflict of Interest}

The authors declare that they have no conflict of interest.

\section{References}

[1] Wisskirchen K, Lucifora J, Michler T, Protzer U. New pharmacological strategies to fight enveloped viruses. Trends Pharmacol Sci 2014; 35 : 470-478

[2] Maginnis MS. Virus-receptor interactions: the key to cellular invasion. J Mol Biol 2018; 430: 2590-2611

[3] Hsu AC. Influenza virus: a master tactician in innate immune evasion and novel therapeutic interventions. Front Immunol 2018; 9: 743

[4] Ezzat K, Pernemalm M, Pålsson S, Roberts TC, Järver P, Dondalska A, Bestas B, Sobkowiak MJ, Levänen B, Sköld M, Thompson EA, Saher O, Kari OK, Lajunen T, Sverremark Ekström E, Nilsson C, Ishchenko Y, Malm T, Wood MJA, Power UF, Masich S, Lindén A, Sandberg JK, Lehtiö J, Spetz AL, El Andaloussi S. The viral protein corona directs viral pathogenesis and amyloid aggregation. Nat Commun 2019; 10: 2331

[5] Derksen A, Kühn J, Hafezi W, Sendker J, Ehrhardt C, Ludwig S, Hensel A. Antiviral activity of hydroalcoholic extract from Eupatorium perfoliatum $\mathrm{L}$. against the attachment of influenza A virus. J Ethnopharmacol 2016; 188: $144-152$

[6] Kim S], Lee JW, Eun YG, Lee KH, Yeo SG, Kim SW. Pretreatment with a grape seed proanthocyanidin extract downregulates proinflammatory cytokine expression in airway epithelial cells infected with respiratory syncytial virus. Mol Med Rep 2019; 19: 3330-3336

[7] Derksen A, Hensel A, Hafezi W, Herrmann F, Schmidt T], Ehrhardt C, Ludwig S, Kühn J. 3-O-galloylated procyanidins from Rumex acetosa L. inhibit the attachment of influenza A virus. PLoS One 2014; 9: e110089

[8] Gescher K, Hensel A, Hafezi W, Derksen A, Kühn J. Oligomeric proanthocyanidins from Rumex acetosa $\mathrm{L}$. inhibit the attachment of herpes simplex virus type-1. Antiviral Res 2011; 89: 9-18

[9] Gescher K, Kühn J, Hafezi W, Louis A, Derksen A, Deters A, Lorentzen E, Hensel A. Inhibition of viral adsorption and penetration by an aqueous extract from Rhododendron ferrugineum $L$. as antiviral principle against herpes simplex virus type-1. Fitoterapia 2011; 82: 408-413

[10] Gescher K, Kühn J, Lorentzen E, Hafezi W, Derksen A, Deters A, Hensel A. Proanthocyanidin-enriched extract from Myrothamnus flabellifolia Welw. exerts antiviral activity against herpes simplex virus type 1 by inhibition of viral adsorption and penetration. J Ethnopharmacol 2011; 134: 468-474

[11] Soares S, Brandão E, García-Estevez I, Fonseca F, Guerreiro C, Ferreira-daSilva F, Mateus N, Deffieux D, Quideau S, de Freitas V. Interaction between Ellagitannins and salivary proline-rich proteins. J Agric Food Chem 2019; 67: 9579-9590

[12] Zálešák F, Bon DJD, Pospíšil J. Lignans and neolignans: Plant secondary metabolites as a reservoir of biologically active substances. Pharmacol Res 2019; 146: 104284

[13] Kaplan IW. Condylomata acuminata. New Orl Med Surg J 1942; 94: 388395
[14] Bao XQ, Liu GT. Bicyclol: a novel antihepatitis drug with hepatic heat shock protein 27/70-inducing activity and cytoprotective effects in mice. Cell Stress Chaperones 2008; 13: 347-355

[15] Huang MH, Li H, Xue R, Li J, Wang L, Cheng J, Wu Z, Li W, Chen J, Lv X, Li Q, Lan P, Zhao L, Yang Y, Peng Z, jiang J. Up-regulation of glycolipid transfer protein by bicyclol causes spontaneous restriction of hepatitis C virus replication. Acta Pharm Sin B 2019; 9: 769-781

[16] Schröder HC, Merz H, Steffen R, Müller WE, Sarin PS, Trumm S, Schulz J, Eich $E$. Differential in vitro anti-HIV activity of natural lignans. Z Naturforsch C 1990; 45: 1215-1221

[17] Eich E, Pertz H, Kaloga M, Schulz J, Fesen MR, Mazumder A, Pommier Y. (-)-Arctigenin as a lead structure for inhibitors of human immunodeficiency virus type-1 integrase. J Med Chem 1996; 39: 86-95

[18] Loizzo MR, Saab AM, Tundis R, Statti GA, Menichini F, Lampronti I, Gambari R, Cinatl J, Doerr HW. Phytochemical analysis and in vitro antiviral activities of the essential oils of seven Lebanon species. Chem Biodivers 2008; 5: 461-470

[19] Reichling J, Schnitzler P, Suschke U, Saller R. Essential oils of aromatic plants with antibacterial, antifungal, antiviral, and cytotoxic properties an overview. Forsch Komplementmed 2009; 16: 79-90

[20] Li Y, Lai Y, Wang Y, Liu N, Zhang F, Xu P. 1,8-cineol protect against influenza-virus-induced pneumonia in mice. Inflammation 2016; 39: 15821593

[21] Nüssing S, Sant S, Koutsakos M, Subbarao K, Nguyen THO, Kedzierska K. Innate and adaptive T cells in influenza disease. Front Med 2018; 12: 3447

[22] Schmidt S, Tramsen L, Rais B, Ullrich E, Lehrnbecher T. Natural killer cells as a therapeutic tool for infectious diseases - current status and future perspectives. Oncotarget 2018; 9: 20891-20907

[23] Gyurova IE, Ali A, Waggoner SN. Natural killer cell regulation of B cell responses in the context of viral infection. Viral Immunol 2020; 33: 334341

[24] Bähr I, Spielmann ], Quandt D, Kielstein H. Obesity-associated alterations of natural killer cells and immunosurveillance of cancer. Front Immunol 2020; 11: 245

[25] Hui DS, Lee N, Chan PK, Beigel JH. The role of adjuvant immunomodulatory agents for treatment of severe influenza. Antiviral Res 2018; 150: 202-216

[26] Nicholls JM, Poon LLM, Lee KC, Ng WF, Lai ST, Leung CY, Chu CM, Hui PK, Mak KL, Lim W, Yan KW, Chan KH, Tsang NC, Guan Y, Yuen KY, Peiris JS. Lung pathology of fatal severe acute respiratory syndrome. Lancet 2003; 361: 1773-1778

[27] Tay MZ, Poh CM, Rénia L, MacAry PA, Ng LFP. The trinity of COVID-19: immunity, inflammation and intervention. Nat Rev Immunol 2020. doi:10.1038/s41577-010-0311-8

[28] Wang K, Conlon M, Ren W, Chen BB, Bączek T. Natural products as targeted modulators of the immune system. J Immunol Res 2018; 2018: 7862782

[29] Spelman K, Burns ], Nichols D, Winters N, Ottersberg S, Tenborg M. Modulation of cytokine expression by traditional medicines: a review of herbal immunomodulators. Altern Med Rev 2006; 11: 128-150

[30] Pleschka S, Stein M, Schoop R, Hudson JB. Anti-viral properties and mode of action of standardized Echinacea purpurea extract against highly pathogenic avian influenza virus (H5N1, H7N7) and Swine-Origin H1N1 (S-OIV). Virol J 2009; 6: 197

[31] Park S, Lee MS, Jung S, Lee S, Kwon O, Kreuter MH, Perrinjaquet-Moccetti T, Min B, Yun SH, Kim Y. Echinacea purpurea protects against restraint stress-induced immunosuppression in BALB/C Mice. J Med Food 2018; 21: $261-268$

[32] Hudson JB. Applications of the phytomedicine Echinacea purpurea (Purple Coneflower) in infectious diseases. J Biomed Biotechnol 2012; 2012: 769896 
[33] Sharma M, Anderson SA, Schoop R, Hudson JB. Induction of multiple pro-inflammatory cytokines by respiratory viruses and reversal by standardized Echinacea, a potent antiviral herbal extract. Antiviral Res 2009; 83: $165-170$

[34] Woelkart K, Linde K, Bauer R. Echinacea for preventing and treating the common cold. Planta Med 2008; 74: 633-637

[35] Schoop R, Klein P, Suter A, Johnston SL. Echinacea in the prevention of induced rhinovirus colds: a meta-analysis. Clin Ther 2006; 28: 174-183

[36] Goel V, Lovlin R, Barton R, Lyon MR, Bauer R, Lee TDG, Basu TK. Efficacy of a standardized echinacea preparation (Echinilin) for the treatment of the common cold: a randomized, double-blind, placebo-controlled trial. J Clin Pharm Ther 2004; 29: 75-83

[37] Woelkart K, Bauer R. The role of alkamides as an active principle of echinacea. Planta Med 2007; 73: 615-623

[38] Raduner S, Majewska A, Chen JZ, Xie XQ, Hamon J, Faller B, Altmann KH, Gertsch J. Alkylamides from Echinacea are a new class of cannabinomimetics. Cannabinoid type 2 receptor-dependent and -independent immunomodulatory effects. J Biol Chem 2006; 281: 14192-14206

[39] World Health Organization (WHO). WHO global report on traditional and complementary medicine 2019. Available at https://www.who. int/publications-detail/who-global-report-on-traditional-andcomplementary-medicine-2019. Accessed May 3, 2020

[40] Luo H, Tang QL, Shang YX, Liang SB, Yang M, Robinson N, Liu JP. Can Chinese medicine be used for prevention of Corona virus disease 2019 (COVID-19)? A review of historical classics, research evidence and current prevention programs. Chin J Integr Med 2020; 26: 243-250

[41] Leung PC. The efficacy of Chinese medicine for SARS: a review of Chinese publications after the crisis. Am J Chin Med 2007; 35: 575-581

[42] Yang Y, Islam MS, Wang J, Li Y, Chen X. Traditional Chinese medicine in the treatment of patients infected with 2019-new Coronavirus (SARS-CoV-2): A review and perspective. Int J Biol Sci 2020; 16: 17081717

[43] Luo Y, Wang CZ, Hesse-Fong J, Lin JG, Yuan CS. Application of Chinese medicine in acute and critical medical conditions. Am J Chin Med 2019; 47: $1223-1235$

[44] Ang L, Lee HW, Choi JY, Zhang J, Soo Lee M. Herbal medicine and pattern identification for treating COVID-19: a rapid review of guidelines. Integr Med Res 2020; 9: 100407

[45] Li SY, Chen C, Zhang HQ, Guo HY, Wang H, Wang L, Zhang X, Hua SN, Yu J, Xiao PG, Li RS, Tan X. Identification of natural compounds with antiviral activities against SARS-associated coronavirus. Antiviral Res 2005; 67: $18-23$
[46] Liu S, Wei W, Shi K, Cao X, Zhou M, Liu Z. In vitro and in vivo anti-hepatitis $B$ virus activities of the lignan niranthin isolated from Phyllanthus niruri $\mathrm{L}$. J Ethnopharmacol 2014; 155: 1061-1067

[47] Huang RL, Huang YL, Ou JC, Chen CC, Hsu FL, Chang C. Screening of 25 compounds isolated from Phyllanthus species for anti-human hepatitis B virus in vitro. Phytother Res 2003; 17: 449-453

[48] Soto-Acosta R, Bautista-Carbajal P, Syed GH, Siddiqui A, Del Angel RM. Nordihydroguaiaretic acid (NDGA) inhibits replication and viral morphogenesis of dengue virus. Antiviral Res 2014; 109: 132-140

[49] Merino-Ramos T, Jiménez de Oya N, Saiz JC, Martín-Acebes MA. Antiviral activity of Nordihydroguaiaretic acid and its derivative Tetra-O-Methyl Nordihydroguaiaretic acid against West Nile virus and Zika virus. Antimicrob Agents Chemother 2017; 61: e00376-17

[50] Wang S, Le TQ, Kurihara N, Chida J, Cisse Y, Yano M, Kido H. Influenza virus-cytokine-protease cycle in the pathogenesis of vascular hyperpermeability in severe influenza. J Infect Dis 2010; 202: 991-1001

[51] Kuo YC, Kuo YH, Lin YL, Tsai W]. Yatein from Chamaecyparis obtusa suppresses herpes simplex virus type 1 replication in HeLa cells by interruption the immediate-early gene expression. Antiviral Res 2006; 70: 112120

[52] Martinez-Lopez A, Persaud M, Chavez MP, Zhang H, Rong L, Liu S, Wang TT, Sarafianos SG, Diaz-Griffero F. Glycosylated diphyllin as a broad-spectrum antiviral agent against Zika virus. EBioMedicine 2019; 47: 269-283

[53] Zhang H], Rumschlag-Booms E, Guan YF, Liu KL, Wang DY, Li WF, van Nguyen H, Cuong NM, Soejarto DD, Fong HHS, Rong L. Anti-HIV diphyllin glycosides from Justicia gendarussa. Phytochemistry 2017; 136: 94100

[54] Liu GT. Bicyclol: a novel drug for treating chronic viral hepatitis B and C. Med Chem 2009; 5: 29-43

[55] Chen M, Kilgore N, Lee KH, Chen DF. Rubrisandrins A and B, lignans and related anti-HIV compounds from Schisandra rubriflora. J Nat Prod 2006; 69: 1697-1701

[56] Li ], Meng AP, Guan XL, Li ], Wu Q, Deng SP, Su X], Yang RY. Anti-hepatitis $B$ virus lignans from the root of Streblus asper. Bioorg Med Chem Lett 2013; 23: 2238-2244

[57] Wen CC, Kuo YH, Jan JT, Liang PH, Wang SY, Liu HG, Lee CK, Chang ST, Kuo C], Lee SS, Hou CC, Hsiao PW, Chien SC, Shyur LF, Yang NS. Specific plant terpenoids and lignoids possess potent antiviral activities against severe acute respiratory syndrome coronavirus. J Med Chem 2007; 50: 4087-4095 